FLUOXETINE AND ZEBRAFISH AGGRESSION

1 Running head: FLUOXETINE AND ZEBRAFISH AGGRESSION

2

3

Acute fluoxetine differently affects aggressive display in zebrafish phenotypes

6

${ }^{1}$ Laboratório de Neurociências e Comportamento "Frederico Guilherme Graeff”,

8 Departamento de Morfologia e Ciências Fisiológicas, Campus VIII/Marabá, Universidade do

$10{ }^{2}$ Programa de Pós-Graduação em Biodiversidade e Biotecnologia - Rede BIONORTE

$11{ }^{3}$ Programa de Pós-Graduação em Neurociências e Comportamento, Universidade Federal do

${ }^{4}$ Laboratório de Neurociências e Comportamento, Instituto de Estudos em Saúde e 


\section{Acute fluoxetine differently affects aggressive display in zebrafish phenotypes}

17 Hellen Pereira Barbosa ${ }^{\mathbf{1}}$, Monica Gomes Lima ${ }^{\mathbf{1 2}}$, Caio Maximino $\mathbf{2}^{\mathbf{3}, 4^{4 *}}$

19 ' Laboratório de Neurociências e Comportamento "Frederico Guilherme Graeff",

20 Departamento de Morfologia e Ciências Fisiológicas, Campus VIII/Marabá, Universidade do

21 Estado do Pará, Marabá/PA, Brazil

$22{ }^{2}$ Programa de Pós-Graduação em Biodiversidade e Biotecnologia - Rede BIONORTE

$23{ }^{3}$ Programa de Pós-Graduação em Neurociências e Comportamento, Universidade Federal do

24 Pará, Belém/PA, Brazil

$25{ }^{4}$ Laboratório de Neurociências e Comportamento, Instituto de Estudos em Saúde e

26 Biológicas, Universidade Federal do Sul e Sudeste do Pará, Marabá/PA, Brazil

\section{$31 *$ Corresponding author}

32 Caio Maximino

33 Laboratório de Neurociências e Comportamento - Instituto de Estudos em Saúde e

34 Biológicas, Universidade Federal do Sul e Sudeste do Pará, Unidade III

35 Av. dos Ipês, S/N, s/ CEP, Bairro Cidade Jardim, Marabá/PA, Brazil

36 cmaximino@unifesspa.edu.br 


\section{Abstract}

38 Zebrafish have been introduced as a model organism in behavioral neuroscience and

39 biological psychiatry, increasing the breadth of findings using fish to study the neurobiology

40 of aggression. Phenotypic differences between leopard and longfin zebrafish were exploited

41 in order to elucidate the role of phasic serotonin in aggressive displays on this species. The

42 present study revealed differences in aggressive display between leopard and longfin

43 zebrafish, and a discrepant effect of acute fluoxetine in both populations. In mirror-induced

44 aggression, leopard animals showed higher display latencies than longfin, as well as lower

45 display duration and frequency (Experiment 1). Moreover, $2.5 \mathrm{mg} / \mathrm{kg}$ fluoxetine decreased

46 the duration and frequency of display in longfin, but not leopard; and $5 \mathrm{mg} / \mathrm{kg}$ fluoxetine

47 increased display frequency in leopard, but not longfin (Experiment 2). It is suggested that

48 zebrafish from the longfin phenotype show more aggressive motivation and readiness in the

49 mirror-induced aggression test that leopard, and that acute fluoxetine increases aggression in

50 leopard and decreased it in longfin zebrafish.

51 Keywords: Zebrafish; Aggressive display; Serotonin; Fluoxetine; Phenotypic

52 differences

53 


\section{1. Introduction}

The biological comprehension of factors underlying aggression is still limited (Miczek et al., 2007), even though a range of mental disorders present aggression as a symptom (Krakowski, Volavka, \& Brizer, 1986). Despite the paucity of neurobiological data on aggression, a role for monoamines has been proposed (Miczek et al., 2007; Takahashi, Quadros, Almeida, \& Miczek, 2011). In most animal models, acutely increasing the

61 serotonergic transmission inhibits aggressive behavior (Takahashi et al., 2011); a metanalysis of preclinical studies demonstrated that, across species, pharmacologically increasing 5-HT

63 levels inhibits aggression (Carrillo, Ricci, Coppersmith, \& Melloni Jr., 2009).

While this observation appears to hold for most studies, some controversies and gaps appear in the literature, especially in basal vertebrates such as fish. For example, in the

66 metanalysis by Carrillo et al. (2009), 5-HT decreased aggression in wrasses and trouts, but not in the Siamese fighting fish. Zebrafish have been introduced as a model organism in

68 behavioral neuroscience and biological psychiatry (Norton \& Bally-Cuif, 2010; Stewart et al.,

69 2015), increasing the relevance of findings using fish to study the neurobiology of 70 aggression.

A role for 5-HT in zebrafish aggressive behavior has been suggested by

72 neurochemical studies. After eliciting an aggressive display towards a mirror (mirror-induced

73 aggression, MIA), 5-HT levels were increased in the telencephalon, while 5-HIAA was

74 increased in the optic tectum of zebrafish (Teles, Dahlbom, Winberg, \& Oliveira, 2013). Male

75 and female zebrafish respond to agonistic encounters in a similar fashion; nonetheless, males

76 present higher 5-HT turnover in the forebrain in relation to females, suggesting that

77 aggressive bouts could be more stressful to males than females (Dahlbom, Backström, 
78 Lundstedt-Enkel, \& Winberg, 2012). Filby et al. (2010) demonstrated that dominant males

79 show an overexpression of genes associated with the serotonergic system in the

80 hypothalamus, including tphlb and htrlaa, while females showed overexpression of tph2,

81 htrlaa, slc6a4a, and mao in the hypothalamus and tphla and tph2 in the telencephalon.

82 While these results suggest that aggressive behavior can be linked to differences in the 83 serotonergic system - especially in the context of dominance hierarchies -, a causal 84 relationship is more tenuous. Filby et al. (2010) treated dominant male zebrafish with 85 fluoxetine ( 3 or $4.5 \mu \mathrm{g} / \mathrm{L}$ ), without effects on aggressive behavior in a dyadic encounter; 86 however, a similar concentration $(3 \mu \mathrm{g} / \mathrm{L})$ decreased aggressive displays in the MIA (W. H. J. 87 Norton et al., 2011). Using a much higher concentration (5 mg/L), Theodoridi et al. (2017) 88 were able to inhibit attacks and chasing behavior in dominant animals in dyads. The lack of 89 consistency could be due to dosing, behavioral paradigms (e.g., MIA vs. dyadic encounters), 90 or other variables.

91 Recent studies also showed that 5-HT levels are lower in zebrafish with the leopard 92 phenotype than in animals with the longfin phenotype, an alteration that is accompanied by 93 increased monoamine oxidase activity (Maximino, Puty, Oliveira, \& Herculano, 2013). These 94 neurochemical differences were accompanied by increased anxiety-like behavior that is 95 rescued by fluoxetine treatment (Maximino, Puty, Oliveira, et al., 2013). Interestingly, in 96 longfin animals fluoxetine increases anxiety, and 5-HT levels are negatively correlated with 97 anxiety-like behavior; it is possible that embryological differences in the serotonergic system 98 produce opposite adult phenotypes.

99 These phenotypic differences are exploited in the present work to clarify the role of 100 phasic serotonin on aggressive displays in zebrafish. We hypothesized that the 
101 hyposerotonergic phenotype of leopard zebrafish would produce increased aggressive

102 behavior, and that fluoxetine would rescue this phenotype. The experimental evidence

103 produced in the present work contradicted this hypothesis, since longfin were shown to

104 display more aggressive motivation and readiness in the mirror-induced aggression test than

105 leopard zebrafish, and since acute fluoxetine increased aggression in leopard animals and

106 decreased it in longfin zebrafish. This manuscript is a complete report of all the studies

107 performed to test the effect of skin phenotype and fluoxetine on aggressive behavior. We

108 report how we determined our sample size, all data exclusions (if any), all manipulations, and

109 all measures in the study.

110

\section{2. Methods}

112 2.1. Animals, housing, and baseline characteristics

113 Outbred populations were used due to their increased genetic variability, decreasing

114 the effects of random genetic drift which could lead to the development of uniquely heritable

115 traits (Parra, Adrian Jr, \& Gerlai, 2009; Speedie \& Gerlai, 2008). Thus, the animals used in

116 the experiments are expected to better represent the natural populations in the wild. Adult

117 zebrafish from the wildtype strain (longfin and leopard phenotypes) were used in this

118 experiment. Animals were bought from a commercial vendor, and arrived in the laboratory

119 with an approximate age of 3 months (standard length $=13.2 \pm 1.4 \mathrm{~mm}$ ), and were

120 quarantined for two weeks; the experiment began when animals had an approximate age of 4

121 months (standard length $=23.0 \pm 3.2 \mathrm{~mm}$ ). Animals were kept in mixed-sex tanks during

122 acclimation, with an approximate ratio of 50 male:50 female. Both phenotypes were kept in

123 the same tank before experiments. The breeder was licensed for aquaculture under Ibama's 
124 (Instituto Brasileiro do Meio Ambiente e dos Recursos Naturais Renováveis) Resolution

125 95/1993. Animals were group-housed in $40 \mathrm{~L}$ tanks, with a maximum density of 25 fish per

126 tank, for at least 2 weeks before experiments begun. Tanks were filled with non-chlorinated

127 water at room temperature $\left(28^{\circ} \mathrm{C}\right)$ and a $\mathrm{pH}$ of 7.0-8.0. Lighting was provided by fluorescent

128 lamps in a cycle of 14-10 hours (LD), according to standards of care for zebrafish (Lawrence,

129 2007). Water quality parameters were as follows: $\mathrm{pH}$ 7.0-8.0; hardness 100-150 mg/L

$130 \mathrm{CaCO}$; dissolved oxygen 7.5-8.0 mg/L; ammonia and nitrite $<0.001 \mathrm{ppm}$. All manipulations

131 minimized their potential suffering of animals, and followed Brazilian legislation (Conselho

132 Nacional de Controle de Experimentação Animal - CONCEA, 2017). Animals were used for

133 only one experiment and in a single behavioral test, to reduce interference from apparatus

134 exposure.

135

136 2.2. Mirror-induced aggression

137 The protocol for mirror-induced aggression was adapted from Norton et al. (2011).

138 Animals were individually transferred to a tank $(15 \times 10 \times 30 \mathrm{~cm})$ containing $1 \mathrm{~L}$ of holding

139 tank water. The tank was lit from above with white light (445 \pm 56 lumens). Tanks were not

140 aerated during testing, so as not to disturb the animals. However, system water, which shows

141 adequate D.O. levels (7.5-8.0 mg/L), was used thoughout the experiments. Animals were

142 allowed to acclimate to the tank for $5 \mathrm{~min}$; after that, a mirror was positioned on the outside

143 of the tank (on the narrower side), in an angle of $22.5^{\circ}$. All steps of the experiment were

144 executed under constant Gaussian white noise ( $55 \pm 2.5 \mathrm{~dB}$ above the tank). Behavior was

145 recorded with a digital video camera (Samsung ES68) positioned in the wider side of the

146 tank, and analyzed by observers blind to treatment using the event-recording software X-Plo- 
147 Rat (https://github.com/lanec-unifesspa/x-plo-rat). The following endpoints were analyzed:

148 time in the square nearest to the mirror (s); frequency $(\mathrm{N})$ and duration (s) of aggressive

149 display; total number of squares crossed (N). Aggressive display was defined as a swimming 150 posture with erect dorsal, caudal, pectoral, and anal fins (Gerlai, Lahav, Guo, \& Rosenthal, $1512000)$.

152

Datasets and scripts for all analyses are available from https://github.com/lanec-

155 unifesspa/5HT-aggression (doi: 10.5281/zenodo.1006701).

\subsection{Experiment 1}

159 regarding the effects of fluoxetine on total time in broadside display in Betta splendens,

160 reported by Lynn et al. (2007); as a result, the closest endpoint (time on display) was chosen

161 as the primary endpoint, and calculations for sample sizes are valid only for that endpoint.

162 Calculations were based on Rosner's (2016) method for comparing two means, and assumed

$163 \alpha=0.05$ and power $80 \%$ on a two-tailed analysis. Based on these calculations, 15 animals

164 were used in each group in Experiment 1. Animals were derived from the stock population

165 described in section 2.1, and displayed either the longfin (Group LOF) or leopard (Group

166 LEO) phenotypes. Animals were randomly drawn from the tank immediately before testing,

167 and the order with which phenotypes were tested was randomized via generation of random 
168

169

numbers using the randomization tool in http://www.randomization.com/. Blinding was not possible, due to the obvious differences in skin phenotype.

Experimental design and statistical analysis. Animals were allocated to each group according to phenotype. Immediately after being drawn from the tank, animals were individually transported to the experiment room, and left undisturbed for $30 \mathrm{~min}$. After this interval, animals were exposed to the MIA test, described above. Differences between groups were analyzed using Approximative Two-Sample Fisher-Pitman Permutation Tests 10,000 Monte-Carlo re-samplings, using the R package 'coin' (Hothorn, Hornik, van de Wiel, \& Zeileis, 2006). The data analyst was blinded to phenotype by using coding to reflect treatments in the resulting datasets; after analysis, data was unblinded. Data are presented using individual dot plots combined with boxplots. Effect sizes are noted in the text as Cohen's d.

\subsection{Experiment 2}

Sample size calculation and groups. In the absence of similar experiments in the literature, sample sizes were calculated based on the assumption of fixed effect sizes for both the phenotype and the dose factors, with a projected effect size of 0.4 , and $80 \%$ power; calculations were made using the R package 'pwr2' (Lu, Liu, \& Koestler, 2017). Based on these calculations, 10 animals were used in each group in Experiment 1. Animals were derived from the stock population described in section 2.1, and displayed either the longfin (Group LOF) or leopard (Group LEO) phenotypes. Animals were randomly drawn from the tank immediately before testing, and the order with which phenotypes were tested was 
190 randomized via generation of random numbers using the randomization tool in

191 http://www.randomization.com/. Blinding for phenotype was not possible, due to the obvious

192 differences in skin phenotype. Animals from each phenotype were randomly allocated to

193 treatment (vehicle or either fluoxetine dose) via generation of random numbers using the

194 randomization tool in http://www.randomization.com/.

195 Drug treatments. Fluoxetine (FLX) was bought from EMS, dissolved in Cortland's 196 salt solution (Wolf, 1963), and injected intraperitoneally in cold-anesthetised animals (Kinkel, 197 Eames, Philipson, \& Prince, 2010). FLX doses (2.5 and $5.0 \mathrm{mg} / \mathrm{kg}$ ) were based on the 198 demonstration of effect on the light/dark test on longfin (Maximino, Puty, Benzecry, et al., 199 2013) and leopard (Maximino, Puty, Oliveira, et al., 2013) zebrafish. Experimenters were 200 blinded to treatment by coding drug vials.

201 Experimental design and statistical analysis. Animals were allocated to each group 202 according to phenotype. Immediately after being drawn from the tank, animals were 203 individually transported to the experiment room, injected with vehicle or drug, and left 204 undisturbed for $30 \mathrm{~min}$. After this interval, animals were exposed to the MIA test, described 205 above. Differences between groups were analyzed using two-way analyses of variance with 206 robust estimators on Huber's M-estimators, using the R package 'rcompanion' (Mangiafico, 207 2017). P-values were adjusted for the false discovery rate. The data analyst was blinded to 208 phenotype by using coding to reflect treatments in the resulting datasets; after analysis, data 209 was unblinded. Data are presented using individual dot plots combined with boxplots. Effect 210 sizes are reported as partial $\varepsilon^{2}$ values, and were calculated using the R package 'lsr' (Navarro, 211 2015). 


\section{3. Results}

\section{4}

\subsection{Experiment 1}

LEO zebrafish showed longer latencies to display than LOF animals $(\mathrm{Z}=3.3925, \mathrm{p}=$ $0.0005, d=1.5779$; Figure $1 \mathrm{~A})$, as well as shorter display durations $(\mathrm{Z}=-2.5659, \mathrm{p}=<2.2 \mathrm{e}$ $16, d=-1.0605$; Figure $1 \mathrm{~B})$ and frequency $(\mathrm{Z}=-2.7073, \mathrm{p}=0.003, d=-1.1372$; Figure $1 \mathrm{C})$, and time spent near the mirror $(\mathrm{Z}=-3.2284, \mathrm{p}=<2.2 \mathrm{e}-16, d=-1.4593$; Figure 1D). No differences were found in total locomotion $(\mathrm{Z}=-0.69887, \mathrm{p}=0.4965, d=-0.2573$; Figure 1E).

\subsection{Experiment 2}

No main effects of phenotype $\left(\mathrm{p}=0.5736\right.$; partial $\left.\varepsilon^{2}=0.0326\right)$ or FLX dose $(\mathrm{p}=$ 0.5044; partial $\varepsilon^{2}=0.0482$ ) were found for latency, but a significant interaction was found ( $\mathrm{p}$ $=0.0412$; partial $\left.\varepsilon^{2}=0.1622\right)$; nonetheless, post-hoc tests did not detect any differences between groups (Figure 2A). Main effects of phenotype $\left(\mathrm{p}=0.0132\right.$; partial $\left.\varepsilon^{2}=0.2429\right)$ and FLX dose $\left(p=0.0062 ;\right.$ partial $\left.\varepsilon^{2}=0.2297\right)$, as well as an interaction effect $(p=0.009$; partial $\varepsilon^{2}=0.1986$ ), were found for display duration (Figure 2B). Post-hoc tests suggested that FLX (2.5 mg/kg) decreased display duration on LOF, but not LEO ( $\mathrm{p}=0.032 \mathrm{vs} .0 \mathrm{mg} / \mathrm{kg})$. Similarly, main effects of phenotype $\left(\mathrm{p}=0.0458\right.$; partial $\left.\varepsilon^{2}=0.2744\right)$ and FLX dose $(\mathrm{p}=$ 0.004; partial $\left.\varepsilon^{2}=0.2476\right)$, as well as an interaction effect $\left(\mathrm{p}<0.0001\right.$; partial $\left.\varepsilon^{2}=0.3598\right)$, were found for display frequency (Figure 2C); post-hoc tests suggested that FLX ( $5 \mathrm{mg} / \mathrm{kg}$ ) increased display frequency in LEO, but not LOF animals ( $p=0.004 \mathrm{vs} .0 \mathrm{mg} / \mathrm{kg}$ ). No main effects of phenotype $\left(p=0.2692\right.$; partial $\left.\varepsilon^{2}=0.3704\right)$ were found for time near mirror, but a 
235 main effect of FLX dose $\left(p=0.0004\right.$; partial $\left.\varepsilon^{2}=0.0164\right)$ and an interaction effect $(p<$

236 0.0001; partial $\varepsilon^{2}=0.5760$ ); post-hoc tests suggested a inverted-U-shaped curve for FLX-

237 treated LOF (0 vs. $2.5 \mathrm{mg} / \mathrm{kg}: \mathrm{p}=0.0012 ; 0$ vs. $5.0 \mathrm{mg} / \mathrm{kg}: \mathrm{p}=0.0167$ ), while a monotonic

238 increase for FLX-treated LEO (0 vs. $2.5 \mathrm{mg} / \mathrm{kg}: \mathrm{p}=0.0496 ; 0$ vs. $5.0 \mathrm{mg} / \mathrm{kg}: \mathrm{p}<0.0001$ )

239 (Figure 2D). No main or interaction effects were found for total locomotion (Figure 2E).

\section{Discussion}

The present work demonstrated that zebrafish with the leopard skin phenotype show

243 less aggressive readiness and less aggression in relation to longfin animals. Moreover, a

244 different pattern of fluoxetine effects was observed, with fluoxetine decreasing aggressive

245 display (but not readiness) in longfin animals and increasing it in leopard animals. Evidence

246 for dose-dependence was also observed. aggressive behavior (Miczek et al., 2007; Summers \& Winberg, 2006; Takahashi et al., 2011).

In a metanalysis of preclinical studies, Carrillo et al. (2009) demonstrated that, across species, 250 pharmacologically increasing 5-HT levels inhibit aggression. Interestingly, in their

251 metanalysis a species-specific effect was found in fish, with 5-HT decreasing aggression in 252 wrasses and trouts, but not in the Siamese fighting fish (Carrillo et al., 2009). The present 253 study examined only aggressive displays, which was elicited in the mirror-induced aggression

254 test; as a result, dominance hierarchies were not induced. Similar results were observed by 255 Norton et al. (2011), which observed reduced aggressive displays in Tübingen zebrafish 256 treated with fluoxetine. When zebrafish are allowed to form dominance hierarchies, 
257 fluoxetine either produces no effect (Filby et al., 2010, using WIK zebrafish) or reduces 258 aggression in dominant males, but not in subordinates (Theodoridi et al., 2017, undescribed 259 phenotype). Given that these studies used different phenotypes than those reported here, 260 conclusions are limited.

261 Behavioral differences between leopard and longfin phenotypes were observed in 262 zebrafish before (Canzian, Fontana, Quadros, \& Rosemberg, 2017; Egan et al., 2008;

263 Maximino, Puty, Oliveira, et al., 2013; Quadros et al., 2016; https://doi.org/10.1101/055657).

264 Of special relevance is the observation that leopard zebrafish present increased brain 265 monoamine oxidase (MAO) activity that is associated with lower serotonin levels and higher 266 turnover of 5-HT in the brain (Maximino, Puty, Oliveira, et al., 2013; Quadros et al., 2018).

267 This hyposerotonergic profile was also associated with increased anxiety-like behavior that 268 was rescued by fluoxetine treatment (Maximino, Puty, Oliveira, et al., 2013). Moreover, 269 Quadros et al. (2018) also found that leopard to be less aggressive than shortfin zebrafish, 270 suggesting a consistent hypoaggressive phenotype across laboratories, conditions, and 271 background genetics.

These results suggest a serotonin-linked behavioral syndrome in zebrafish that varies 273 across populations. Indeed, the hyperanxious profile observed in leopard (Maximino et al., 274 2013) is also rescued by fluoxetine treatment at the same dose range as that reported here. A 275 variety of studies in Siamese fighting fish (Betta splendens) suggest that fluoxetine reduces 276 aggressive behavior (Dzieweczynski \& Hebert, 2012; Eisenreich \& Szalda-Petree, 2015; 277 Kania, Gralak, \& Wielgosz, 2012) and boldness (Dzieweczynski, Campbell, \& Kane, 2016; 278 Dzieweczynski, Kane, Campbell, \& Lavin, 2016), which could be interpreted as either 279 increased impulsivity or decreased anxiety. The presence of a aggression-boldness syndrome 
280 has long been proposed in as a dimension in fish behavior (Conrad, Weinersmith, Brodin, \& 281 Saltz, 2011), and the literature appears to point to serotonin as an important link in that. 282 Nonetheless, these results must be interpreted with caution, given that the B. splendens 283 experiments were made with chronic fluoxetine treatment (which, along with increased 284 serotonin levels, is thought to induce other long-term neuroadaptations; Castrén \& Antila, 285 2017). Moreover, other experiments with zebrafish (Norton et al., 2010) failed to find an 286 effect of fluoxetine in aggression-boldness - although, again, the use of different strains and 287 phenotypes make it difficult to generalize.

The results from the Carrillo et al. (2009) metanalysis suggested a inhibitory role for 289 phasic serotonin (i.e., 5-HT released by either the aggressive act itself, or by pharmacological 290 manipulations such as fluoxetine); a role for tonic 5-HT, in Betta splendens, was discarded, 291 because neither the 5-HT synthesis inhibitor para-chlorophenylalanine nor the 5-HT 292 precursor L-tryptophan changed display behavior (Clotfelter, O’Hare, McNitt, Carpenter, \& 293 Summers, 2007). If that was also true for zebrafish, differences in aggressive display between 294 leopard and longfin would not be expected, given that these phenotypes differ in serotonergic 295 tone (Maximino, Puty, Oliveira, et al., 2013). While these differences were observed in the 296 present work, they occur in the opposite direction from what would be predicted from 5297 HTergic tone alone (i.e., we should expect leopard zebrafish to be more aggressive if 298 aggression was linearly and negatively related to tone). It is more likely that the 299 normalization of 5-HT levels in leopard after fluoxetine treatment is responsible for increased 300 aggression, while the "extra" 5-HT levels after fluoxetine treatment in longfin reduce its basal 301 aggression levels; as a result, the relationship between aggression and 5-HT levels are to be 302 interpreted as following and inverted-U-shaped distribution (Figure 3). This is also reinforced 
303 by the generally hormetic dose-response curves observed in longfin animals treated with

304 fluoxetine. Alternatively, it is possible that a developmental effect is responsible for these 305 discrepancies.

306 While it might be tempting to attribute these differences to genetic differences across 307 populations, the animals used were not derived from inbred strains. The altered pigmentation 308 observed in our leopard fish has previously been reported, in the Tupfel long-fin (TL) strain, 309 to be due to a mutation in connexin41.8 (Watanabe et al., 2006); nonetheless, it is unknown 310 whether this mutation is present in our animals, or whether this genetic marker is one of 311 many loci that differ between leopard and longfin animals (Gerlai, 2018). These differences 312 make it difficult to make specific genetic inferences regarding the differences observed in the 313 present work. Nonetheless, behavioral differences between leopard and longfin zebrafish 314 were consistently observed across laboratories (and therefore across fish vendors) (Canzian, 315 Fontana, Quadros, \& Rosemberg, 2017; Egan et al., 2008; Maximino et al., 2013; Quadros et 316 al., 2016, 2018), and the effect of phenotype on zMAO activity was observed independently 317 at least twice (Maximino et al., 2013; Quadros et al., 2018), suggesting an important link 318 between the serotonergic system and aggressive behaviors across zebrafish strains.

319 These results are also reminiscent of what is observed in different populations of 320 Astyanax mexicanus. In that species, different populations occupy different niches, and 321 surface-dwelling populations are much more aggressive than cave-dwelling populations 322 (Rétaux \& Elipot, 2013). These differences are related to the density of serotonergic neurons 323 in the hypothalamus, with cavefish showing a higher number of 5-HT neurons in that region 324 (Elipot, Hinaux, Callebert, \& Rétaux, 2013). Moreover, a mutation in the mao gene was 325 found in cavefish that led to an hyperserotonergic phenotype (Elipot et al., 2014). Treating 
326 surface fish with fluoxetine decreases aggression, while in cavefish the drug slightly 327 increases it (Elipot et al., 2013). In the present paper, however, treatment with fluoxetine 328 increased aggression in leopard animals (which show an hyposerotonergic profile in relation 329 to longfin animals; Maximino, Puty, Oliveira, et al., 2013) and decreased it in longfin 330 zebrafish. These differences might be due to the origin of serotonin, since, in Astyanax 331 mexicanus populations, raphe 5-HT levels are unchanged, while hypothalamic 5-HT is 332 increased (Elipot et al., 2013); further experiments are needed to untangle this hypothesis.

333 Interestingly, a different dose-response profile was observed between phenotypes in 334 the present study, with the low dose $(2.5 \mathrm{mg} / \mathrm{kg})$ generally decreasing aggression in longfin 335 and the high dose $(5.0 \mathrm{mg} / \mathrm{kg})$ generally increasing it in leopard. While difficult to explain 336 presently, these results suggest either that an "optimal" serotonergic tone is needed to 337 maintain aggression levels, or that serotonin transporters are desensitized or downregulated in 338 the leopard population. While the first hypothesis is more likely, given the observation of an 339 hyposerotonergic profile in leopard zebrafish (Maximino et al., 2013; Quadros et al., 2018), 340 the current state of the literature and the current data are not enough to assess this.

In conclusion, the present experiments revealed differences in aggressive behavior 342 between leopard and longfin zebrafish, and a discrepant effect of fluoxetine on both 343 populations. These results are relevant to understand the role of tonic and phasic serotonin 344 neurotransmission on aggressive behavior in preclinical models, and might contribute to a 345 better appreciation of the complex roles of this monoamine in controlling vertebrate 346 aggression. 


\section{Acknowledgments}

349 Data packages and statistical analysis scripts for this article can be found at 350 https://dx.doi.org/10.5281/zenodo.1006701.

\section{References}

353 Canzian, J., Fontana, B. D., Quadros, V. A., \& Rosemberg, D. B. (2017). Conspecific alarm 354 substance differently alters group behavior of zebrafish populations: Putative 355 involvement of cholinergic and purinergic signaling in anxiety- and fear-like responses.

356 Behavioural Brain Research, 320, 255-263. https://doi.org/10.1016/j.bbr.2016.12.018

357 Carrillo, M., Ricci, L. A., Coppersmith, G. A., \& Melloni Jr., R. H. (2009). The effect of 358 increased serotonergic neurotransmission on aggression: A critical meta-analytical 359 review of preclinical studies. Psychopharmacology, 205, 349-368.

360 https://doi.org/10.1007/s00213-009-1543-2

361 Castrén, E., \& Antila, H. (2017). Neuronal plasticity and neurotrophic factors in drug 362 responses. Molecular Psychiatry, 22, 1085-1095. https://doi.org/10.1038/mp.2017.61

363 Clotfelter, E. D., O’Hare, E. P., McNitt, M. M., Carpenter, R. E., \& Summers, C. H. (2007).

364 Serotonin decreases aggression via 5-HT1A receptors in the fighting fish Betta

365 splendens. Pharmacology, Biochemistry \& Behavior, 87, 222-231.

366 https://doi.org/10.1016/j.pbb.2007.04.018 
367 Conrad, J. L., Weinersmith, K. L., Brodin, T., \& Saltz, J. B. (2011). Behavioural syndromes in 368 fishes: A review with implications for ecology and fisheries management. Journal of Fish Biology, 78, 395-435. https://doi.org/10.1111/j.1095-8649.2010.02874.x para o cuidado e a utilização de animais para fins científicos e didáticos - DBCA. Anexo I. Peixes mantidos em instalações de instituições de ensino ou pesquisa científica, Pub. L. No. Resolução Normativa 30/2016 (2017). Brasil.

Dahlbom, S. J., Backström, T., Lundstedt-Enkel, K., \& Winberg, S. (2012). Aggression and monoamines: Effects of sex and social rank in zebrafish (Danio rerio). Behavioural Brain Research, 228, 333-338. https://doi.org/10.1016/j.bbr.2011.12.011

Dzieweczynski, T. L., Campbell, B. A., \& Kane, J. L. (2016). Dose-dependent fluoxetine effects on boldness in male Siamese fighting fish. Journal of Experimental Biology, 219, 797-804. https://doi.org/10.1242/jeb.132761

Dzieweczynski, T. L., \& Hebert, O. L. (2012). Fluoxetine alters behavioral consistency of aggression and courtship in male Siamese fighting fish, Betta splendens. Physiology and Behavior, 107, 92-97. https://doi.org/10.1016/j.physbeh.2012.06.007

Dzieweczynski, T. L., Kane, J. L., Campbell, B. A., \& Lavin, L. E. (2016). Fluoxetine exposure impacts boldness in female Siamese fighting fish, Betta splendens. Ecotoxicology, 25, 69-79. https://doi.org/10.1007/s10646-015-1568-8

Eisenreich, B. R., \& Szalda-Petree, A. (2015). Behavioral effects of fluoxetine on aggression and associative learning in Siamese fighting fish (Betta splendens). Behavioural Processes, 121, 37-42. https://doi.org/10.1016/j.beproc.2015.10.008 
389 Elipot, Y., Hinaux, H., Callebert, J., Launay, J.-M., Blin, M., \& Rétaux, S. (2014). A mutation 390 in the enzyme monoamine oxidase explains part of the Astyanax cavefish behavioural $391 \quad$ syndrome. Nature Communications, 5, 3647. https://doi.org/10.1038/ncomms4647

392 Elipot, Y., Hinaux, H., Callebert, J., \& Rétaux, S. (2013). Evolutionary shift from fighting to 393 foraging in blind cavefish through changes in the serotonin network. Current Biology, 394 23, 1-10. https://doi.org/10.1016/j.cub.2012.10.044

395 Filby, A. L., Paull, G. C., Hickmore, T. F., \& Tyler, C. R. (2010). Unravelling the neurophysiological basis of aggression in a fish model. BMC Genomics, 11, 498. https://doi.org/10.1186/1471-2164-11-498 and Behavior, 67, 773-782.

401 Gerlai, R. T. (2018). Reproducibility and replicability in zebrafish behavioral neuroscience research. Pharmacology, Biochemistry \& Behavior, In press. https://doi.org/10.1016/j.pbb.2018.02.005 conditional inference. The American Statician, 60, 257-263. diminishes aggressive behaviour of male Siamese fighting fish (Betta splendens). Journal of Behavioral and Brain Science, 2, 185-190. https://doi.org/10.4236/jbbs.2012.22022 
411 Kinkel, M. D., Eames, S. C., Philipson, L. H., \& Prince, V. E. (2010). Intraperitoneal

412 injection into adult zebrafish. Journal of Visualized Experiments, 42, 2126.

413 https://doi.org/10.3791/2126

414 Krakowski, M., Volavka, J., \& Brizer, D. (1986). Psychopathology and violence: A review of

415 literature. Comprehensive Psychiatry, 27, 131-148. https://doi.org/10.1016/0010-

$416 \quad 440 X(86) 90022-2$

417 Lawrence, C. (2007). The husbandry of zebrafish (Danio rerio): A review. Aquaculture, 269, 418 1-20. https://doi.org/10.1016/j.aquaculture.2007.04.077

419 Lu, P., Liu, J., \& Koestler, D. (2017). pwr2: Power and Sample Size Analysis for One-way 420 and Two-way ANOVA Models. Retrieved from https://cran.r-project.org/package=pwr2

421 Lynn, S. E., Egar, J. M., Walker, B. G., Sperry, T. S., \& Ramenofsky, M. (2007). Fish on 422 Prozac: A simple, noninvasive physiology laboratory investigating the mechanisms of 423 aggressive behavior in Betta splendens. Advances in Physiology Education, 31, 358424 363. https://doi.org/10.1152/advan.00024.2007

425 Mangiafico, S. (2017). rcompanion: Functions to Support Extension Education Program 426 Evaluation. Retrieved from https://cran.r-project.org/package=rcompanion 427 Maximino, C., Puty, B., Benzecry, R., Araujo, J., Lima, M. G., Batista, E. de J. O., ... 428 Herculano, A. M. (2013). Role of serotonin in zebrafish (Danio rerio) anxiety: 429 Relationship with serotonin levels and effect of buspirone, WAY 100635, SB 224289, 430 fluoxetine and para-chlorophenylalanine (pCPA) in two behavioral models. $431 \quad$ Neuropharmacology, 71, 83-97. https://doi.org/10.1016/j.neuropharm.2013.03.006 
432 Maximino, C., Puty, B., Oliveira, K. R. M., \& Herculano, A. M. (2013). Behavioral and neurochemical changes in the zebrafish leopard strain. Genes, Brain and Behavior, 12, 576-582. https://doi.org/10.1111/gbb.12047

Miczek, K. A., de Almeida, R. M. M., Kravitz, E. a, Rissman, E. F., de Boer, S. F., \& Raine, A. (2007). Neurobiology of escalated aggression and violence. Journal of Neuroscience, 27, 11803-11806. https://doi.org/10.1523/JNEUROSCI.3500-07.2007 Adelaide, Adelaide, Australia. ISBN: 978-1-326-18972-3. URL: http://health.adelaide.edu.au/psychology/ccs/teaching/lsr/.

Norton, W., \& Bally-Cuif, L. (2010). Adult zebrafish as a model organism for behavioural genetics. BMC Neuroscience, 11, 90. https://doi.org/10.1186/1471-2202-11-90

Norton, W. H. J., Stumpenhorst, K., Faus-Kessler, T., Folchert, A., Rohner, N., Harris, M. P., ... Bally-Cuif, L. (2011). Modulation of fgfrla signaling in zebrafish reveals a genetic basis for the aggression-boldness syndrome. Journal of Neuroscience, 31, 1379613807. https://doi.org/10.1523/JNEUROSCI.2892-11.2011

448 Parra, K. V, Adrian Jr, J. C., \& Gerlai, R. (2009). The synthetic substance hypoxanthine 3-Noxide elicits alarm reactions in zebrafish (Danio rerio). Behavioural Brain Research, 205, 336-341. https://doi.org/10.1016/j.bbr.2009.06.037

451 Quadros, V. A., Silveira, A., Giuliani, G. S., Didonet, F., SIlveira, A. S., Nunes, M. E., ...

452 Rosemberg, D. B. (2016). Strain- and context-dependent behavioural responses of acute 
453 alarm substance exposure in zebrafish. Behavioural Processes, 122, 1-11.

$454 \quad$ https://doi.org/10.1016/j.beproc.2015.10.014

455 Quadros, V. A., Costa, F. V., Canzian, J., Nogueira, C. W., \& Rosemberg, D. B. (2018).

456 Modulatory role of conspecific alarm substance on aggression and brain monoamine

457 oxidase activity in two zebrafish populations. Progress in Neuro-Psychopharmacology

$458 \quad \&$ Biological Psychiatry. https://doi.org/10.1016/j.pnpbp.2018.03.018.

459 Rétaux, S., \& Elipot, Y. (2013). Feed or fight. A behavioral shift in blind cavefish.

460 Communicative \& Integrative Biology, 6, e23166. https://doi.org/10.4161/cib.23166

461 Rosner, B. (2016). Fundamentals of biostatistics. Cengage Learning.

462 Speedie, N., \& Gerlai, R. (2008). Alarm substance induced behavioral responses in zebrafish 463 (Danio rerio). Behavioural Brain Research, 188, 168-177.

464 https://doi.org/10.1016/j.bbr.2007.10.031

465 Stewart, A. M., Ullmann, J. F. P., Norton, W. H. J., Parker, M. O., Brennan, C. H., Gerlai, R.,

466 \& Kalueff, A. V. (2015). Molecular psychiatry of zebrafish. Molecular Psychiatry, 20,

$467 \quad$ 2-17. https://doi.org/10.1038/mp.2014.128

468 Summers, C. H., \& Winberg, S. (2006). Interactions between the neural regulation of stress

469 and aggression. Journal of Experimental Biology, 209, 4581-4589.

$470 \quad$ https://doi.org/10.1242/jeb.02565

471 Takahashi, A., Quadros, I. M., Almeida, R. M. M. de, \& Miczek, K. A. (2011). Brain

472 serotonin receptors and transporters: Initiation vs . termination of escalated aggression.

473 Psychopharmacology, 213, 183-212. https://doi.org/10.1007/s00213-010-2000-y 
474 Teles, M. C., Dahlbom, S. J., Winberg, S., \& Oliveira, R. F. (2013). Social modulation of 475 brain monoamine levels in zebrafish. Behavioural Brain Research.

476 https://doi.org/10.1016/j.bbr.2013.07.012

477 Theodoridi, A., Tsalafouta, A., \& Pavlidis, M. (2017). Acute exposure to fluoxetine alters

478 aggressive behavior of zebrafish and expression of genes involved in serotonergic

$479 \quad$ system regulation. Frontiers in Neuroscience, 11, Article 223.

$480 \quad$ https://doi.org/10.3389/fnins.2017.00223

481 Watanabe, M., Iwashita, M., Ishii, M., Kurachi, Y., Kawakami, A., Kondo, S., \& Okada, N.

482 (2006). Spot pattern of leopard Danio is caused by mutation in the zebrafish

483 connexin41.8 gene. EMBO Reports, 7, 893-897.

484 https://doi.org/10.1038/sj.embor.7400757

485 Wolf, K. (1963). Physiological salines for freshwater teleosts. Progress in Fish-Culture, 25, $486 \quad 135-140$. 
488 Figure captions

489 Figure 1 - Phenotype differences in (A) latency to display, in s; (B) display duration, in s;

490 (C), display frequency; (D), time spent near the mirror, in s; and (E), total locomotion.

491 Boxplots represent median and interquartile range, with Tukey whiskers.

492

493 Figure 2 - Effects of fluoxetine on the aggressive display of longfin (LOF, dark gray) and

494 leopard (LEO, light gray) zebrafish. (A) latency to display, in s; (B) display duration, in s;

495 (C), display frequency; (D), time spent near the mirror, in s; and (E), total locomotion.

496 Boxplots represent median and interquartile range, with Tukey whiskers. Dots joined by lines

497 represent means.

498

499 Figure 3 - Hypothesized role of the serotonergic tone on the organization of aggressive 500 display in longfin and leopard zebrafish. 

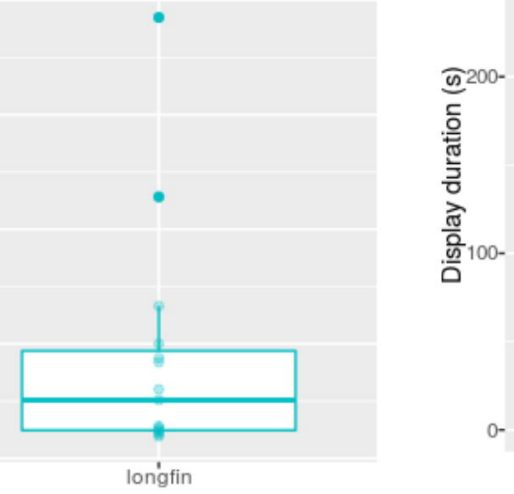

o-

leoṕard

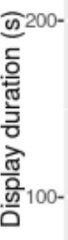

30-

C

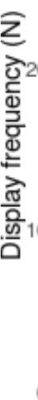

0-

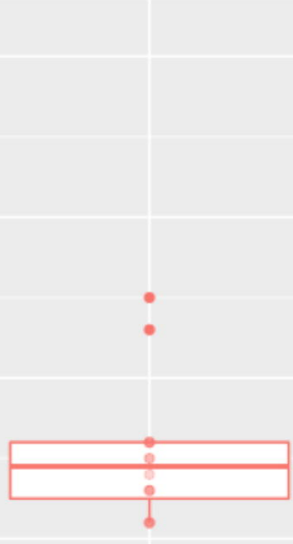

leoṕard

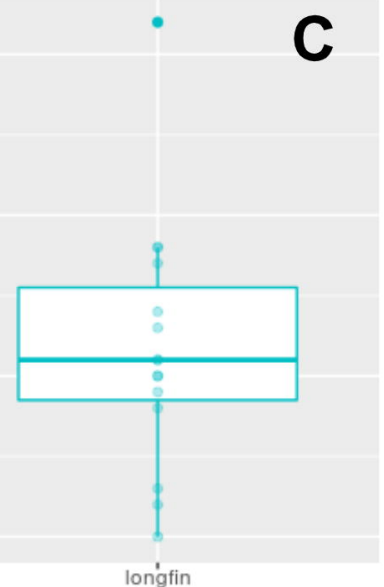

$150-$

- D

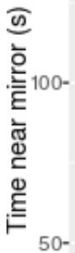
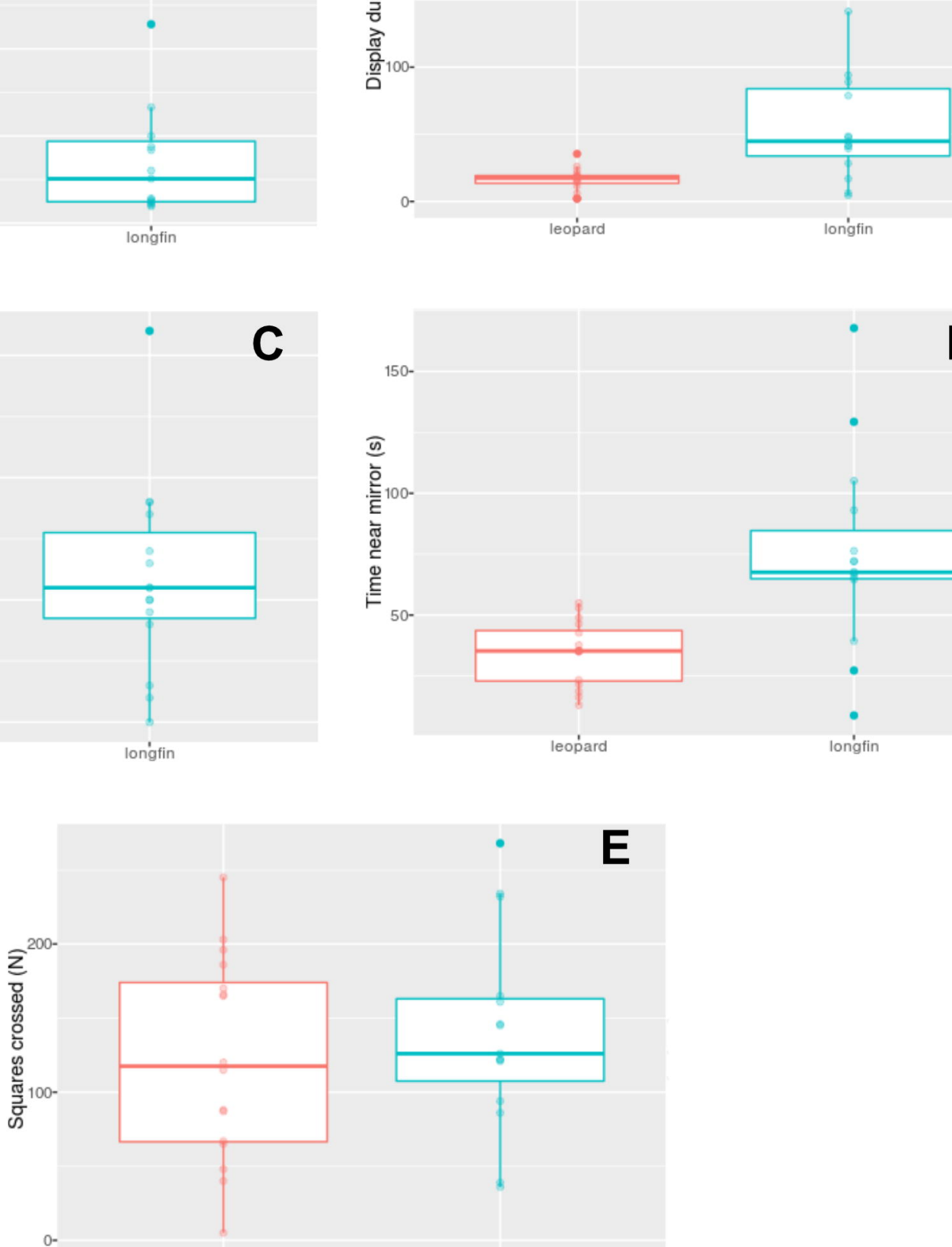

E

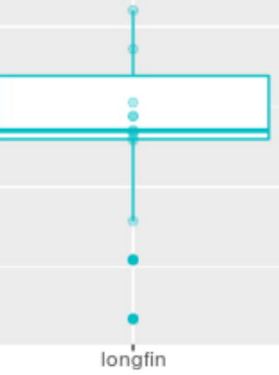


- More 5-HTergic tone

\section{- Less 5-HTergic tone}

- Less aggressive displays

- Less aggressive readiness

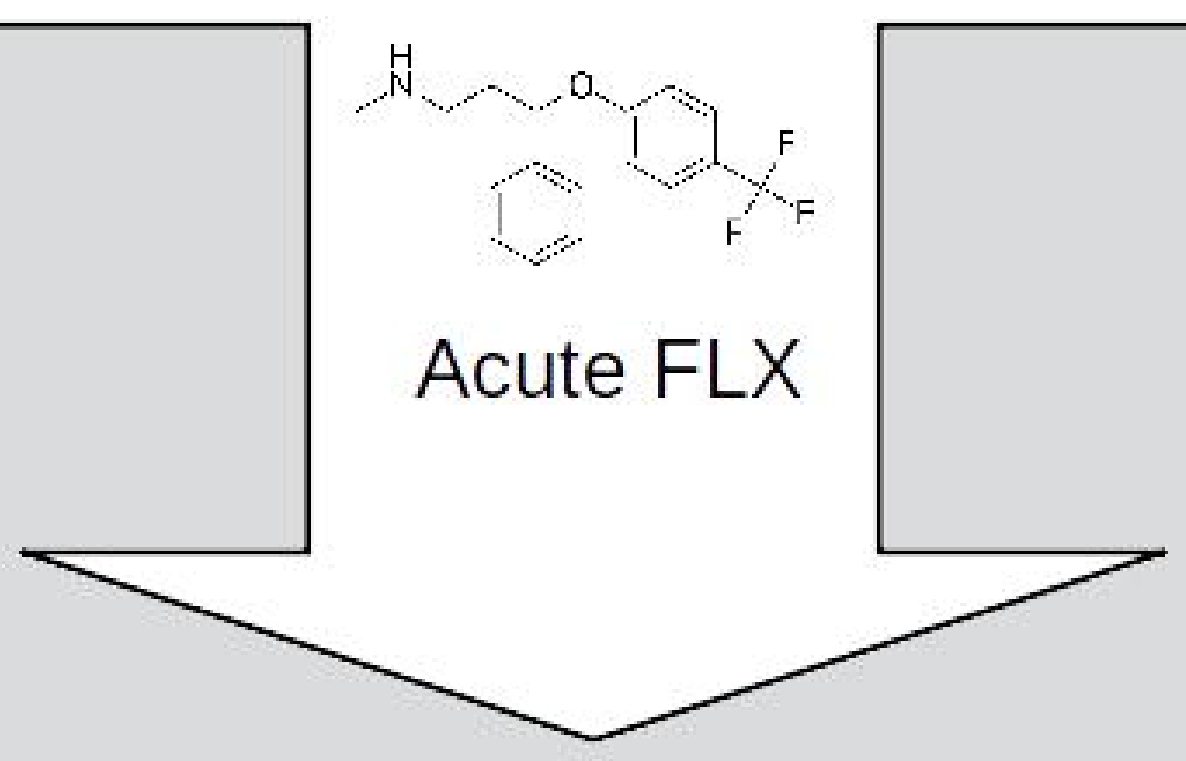

- Too much 5-HT

- Normal 5-HT
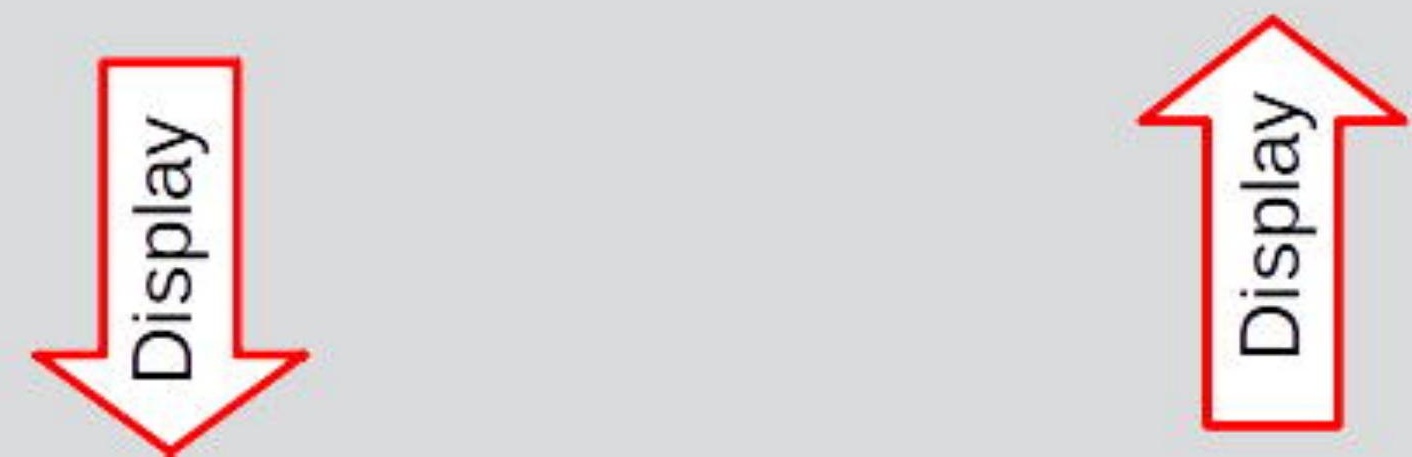